\title{
Effects of Fatty Acid Salts against Trichophyton Violaceum
}

\author{
Mariko ERA ${ }^{1}$, Takayoshi KAWAHARA ${ }^{2}$, Takahide KANYAMA ${ }^{2}$ and Hiroshi MORITA ${ }^{3}$ \\ ${ }^{1}$ Graduate school of Environmental Engineering, The University of Kitakyusyu \\ 2 Shabondama Soap Co., Ltd \\ ${ }^{3}$ Faculty of Environmental Engineering, The University of Kitakyusyu
}

\begin{abstract}
Trichophyton violaceum is an anthropophilic fungus. Dermatophytosis (Tinea) is fungal infection that can infect the scalp, glabrous skin, and nails. In general, Tinea can be spread by skin-to-skin contact or bathroom or floor materials. The treatments of Tinea need antifungal medication and good hygiene environment. The effective antifungal medication and infection prevention, and the creation of antifungal medication with high safety are required. In this study was focused on the antifungal effect of fatty acids potassium salts. The antifungal activity of nine fatty acid salts (butyrate, caproate, caprylate, caprate, laurate, myristate, oleate, linoleate, and linolenate) was tested on the spores of Trichophyton violaceum NBRC 31064. The results show that C6K, C8K, C10K, C12K, $\mathrm{C} 18: 2 \mathrm{~K}, \mathrm{C} 18: 3 \mathrm{~K}$ was the most inhibit $4-\log$ unit $(99.99 \%)$ of the fatty acids potassium incubated time for $10 \mathrm{~min}$. It was observed that $\mathrm{C} 12 \mathrm{~K}$ and $\mathrm{C} 18: 3 \mathrm{~K}$ was most high antifungal activity MIC. Commercially soap was lowest antifungal activity. This is because of the oleic acid is a major component of soap. Although further investigation is necessary to make clear antifungal mechanisms, our results suggest that fatty acid potassium will use to the development of a coating agent such as furniture.
\end{abstract}

\section{Introduction}

Dermatophytes are parasitic fungi that infect skin, hair and nails of both humans and animals [1]. David et al. suggest that dermatophytes infections are caused by 40 species of fungi which are grouped into three genera;Trichophyton, Microsporum and Epidermophyton [2]. Tricophyton violaceum is an anthropophilic dermatophyte. Dermatophyte infections are common worldwide, and infections of skin, hair, and nails caused by Trichophyton .spp [3], [4]. Antifungal agents such as itraconazole, ketoconazole, miconazole, clotrimazole, voriconazole, terbinafine, fluconazole is used as a therapeutic agent. However, although these antifungal therapy is usually well tolerated, the drug may cause gastrointestinal side effects and must be administered for a period of several weeks, making successful treatment of young children potentially difficult. We were searching for an alternative to the more secure and antifungal agents [3], [5], [6].

In this study, we focused on fatty acid salts, which are the main component of soap. Fatty acids, the raw material for the production of fatty acid salts, have been reported to show some antibacterial and antifungal activity. Fatty acids vary in length and degree of saturation, and naturally occurring fatty acids have a chain length of 4 to 28 carbons, which may be saturated or unsaturated [7]. Saturated fatty acids are straight chains and consist of a carbon chain with single bonds, while unsaturated fatty acids contain one or more carbon-carbon double bonds
$(\mathrm{C}=\mathrm{C})$, which introduce fixed bends into the carbon chain [8]. Some report on the antimicrobial and antifungal effect of the fatty acid. For example, Neisseria gonarrhoese and Helicobacter pylori, Aspergillus spp. and Penicillium spp [9]-[11]. A previous study (Era et. al., 2015) indicated that the antifungal activity of nine fatty acid salts was tested on the spores of Penicillium pinophilum NBRC 6345 and Penicillium digitatum NBRC 9651. Potassium caprate showed the strongest antifungal activity at 4 log-units. At incubation times of $180 \mathrm{~min}$, potassium caprylate and potassium laurate showed antifungal activities of 2 log-units against $P$. pinophilum NBRC 6345 [12]. The results confirm the effectiveness of the ability of $\mathrm{C} 10 \mathrm{~K}$ to inhibit fungal growth on orange rind. C10K effectively inhibited $P$. pinophilum NBRC 6345 growth on orange rind [12]. Thus, C10K shows promise as an antifungal agent. This result shows that fatty acid salts prevented fungal growth, and fatty acid salts can be forecasted from its effective antifungal agent for dermatophytes. Dermatophytes can be infected by towels and clothing, while Foot ringworm is infected through shoes, socks and the floor or bathroom floor mats. We believe that the fatty acid salt serve the prevention of dermatophytes infection.

\section{Materials and Methods}

\subsection{Fungus stains}


The spore suspension of T. violaceum NBRC 31064 was obtained from the NBRC (Biological Resource Center, NITE, Tokyo, Japan). The fungus was initially grown on Sabouraud dextrose agar (Nissui Pharmaceutical Co., Ltd., Tokyo, Japan) in the dark and the culture stocks were stored at $4^{\circ} \mathrm{C}$. Plant-pathogenic fungi were routinely sub-cultured on Sabouraud dextrose agar in slants in the dark at $27^{\circ} \mathrm{C}$ so that the fresh cultures were available for later use.

\subsection{Preparation of spore suspensions}

Fungus was grown on Sabouraud dextrose agar slants at $27^{\circ} \mathrm{C}$ until well sporulated, approximately $10-14 \mathrm{~d}$. Spores were harvested in sterile distilled water using a sterile inoculation loop and gentle agitation; $0.9 \% \mathrm{NaCl}$ were added to aid wetting of the spores. The spore concentration was determined by counting using a hemacytometer (Thoma, Sunlead Glass Corp., Saitama, Japan). The initial spore concentration was adjusted to $3.0 \times 10^{4}$ spores $/ \mathrm{mL}$.

\subsection{Source of fatty acids}

Nine fatty acids, butyric acid (C4:0), caproic acid (C6:0), and Iinoleic acid (C18:2) were obtained from Wako Pure Chemical Industries, Ltd., Osaka, Japan. Caprylic acis (C8:0), capric acid (C10:0), lauric acid (C12:0), myristic acid (C14:0), oleic acid (C18:1), and Linolenic acid (C18:3) were obtained from Tokyo Chemical Industry Co., Ltd. Potassium salts of fatty acids were also prepared by mixing fatty acid salt with the $\mathrm{KOH}$ : potassium hydroxide pellets (Wako Pure Chemical Industries, Ltd., Osaka, Japan) and water. Samples were prepared at $350 \mathrm{mM}$ concentrations. The samples were then stirred for $2 \mathrm{~h}$ at $75^{\circ} \mathrm{C}$. $\mathrm{KOH}$ aq was added to yield theoretical neutralization at $\mathrm{pH} 10.5$ of fatty acid salts. Potassium butyrate $(\mathrm{C} 4 \mathrm{~K})$, potassium caproate (C6K), potassium caprylate $(\mathrm{C} 8 \mathrm{~K})$, potassium caprate $(\mathrm{C} 10 \mathrm{~K})$, potassium laurate $(\mathrm{C} 12 \mathrm{~K})$, potassium myristate $(\mathrm{C} 14 \mathrm{~K})$, potassium oleate $(\mathrm{C} 18: 1 \mathrm{~K})$, potassium linoleate $(\mathrm{C} 18: 2 \mathrm{~K})$, potassium linolenate $(\mathrm{C} 18: 3 \mathrm{~K})$, and the blank were all adjusted using a $\mathrm{KOH}$ pH-adjusted solution $(\mathrm{pH} 10.5)$ [12]. All fatty acid salts and the $\mathrm{KOH} \mathrm{pH}$ - adjusted solution were filter-sterilized at low temperature $\left(4-6^{\circ} \mathrm{C}\right)$ using a $0.20-\mu \mathrm{m}$ Millipore filter (Toyo Roshi Kaisya, Ltd., Tokyo, Japan).

\subsection{Effect of fatty acid salts on fungal spores}

Solutions of $400 \mu \mathrm{L}$ of fatty acid salts (final concentration of $175 \mathrm{mM}$ in the tubes) and $400 \mu \mathrm{L}$ of the spore suspension $\left(3.0 \times 10^{4}\right.$ spores $\left./ \mathrm{mL}\right)$ were prepared in $1.5 \mathrm{~mL}$ plastic tubes. Spores mixed with the $\mathrm{KOH} \mathrm{pH}-$ adjusted solution were used as controls [12]. Final $\mathrm{pH}$ of all samples were a range of $\mathrm{pH}$ 9.2-10.8. The mixtures were incubated at $25^{\circ} \mathrm{C}$. Samples were counted at 0,10 , 60 , and $180 \mathrm{~min}$ by plating $(100 \mu \mathrm{L})$ on Sabouraud dextrose agar. Fungal colonies were counted after incubation for $3 \mathrm{~d}$ or $7 \mathrm{~d}$ at $27^{\circ} \mathrm{C}$. Viable counts $(\log 10$ $\mathrm{CFU})$ of spore was subtracted from the viable count of the control ( $\log 10 \mathrm{CFU})$, and the difference was used as a measure of the antifungal activity. All experiments were performed at least thrice.

\subsection{Determination of minimum inhibitory concentrations (MICs)}

The MIC is defined as the lowest concentration of drug sufficient for inhibiting visible growth of spores after $10 \mathrm{~min}$ of incubation. MICs against fungi were determined using the two-fold dilution method [13], [14]. Each fatty acid salt was separately inoculated with 400 $\mu \mathrm{L}$ of $T$. violaceum NBRC 31064 at $3.0 \times 10^{4}$ spores $/ \mathrm{mL}$. $1.5 \mathrm{~mL}$ plastic tubes containing $400 \mu \mathrm{L}$ of each of fatty acid salts were inoculated separately with $400 \mu \mathrm{L}$ of the fungi. The tubes, each containing a total volume of 800 $\mu \mathrm{L}$, were incubated at $25^{\circ} \mathrm{C}$ for each organism for $10 \mathrm{~min}$. After incubation, samples were plating on Sabouraud dextrose agar, incubated at $27^{\circ} \mathrm{C}$ for $7 \mathrm{~d}$, and then examined for the growth of spores. Following incubation, the end point was visually assessed and expressed in $\mathrm{mM}$. The lowest concentration of the antifungal treatment that inhibited visible growth of the fingi after incubation was taken as the MIC of the treatment [14].

\subsection{Effect of $\mathrm{C} 12 \mathrm{~K}$ combined with other fatty acid salts}

C12K was mixed with short-chain fatty acid salts (C4K, C6K), medium-chain fatty acid salts (C8K, C10K) or long-chain fatty acid salts $(\mathrm{C} 14 \mathrm{~K}, \mathrm{C} 18: 1 \mathrm{~K}, \mathrm{C} 18: 2 \mathrm{~K}$, $\mathrm{C} 18: 3 \mathrm{~K}$ ); final concentrations of each fatty acid salt of $0.175,1.75,17.5,35,87.5,130 \mathrm{mM}$. Final concentration of $\mathrm{C} 12 \mathrm{~K}$ was $5.5 \mathrm{mM}$. These samples were used to measure the antifungal activity of $\mathrm{C} 12 \mathrm{~K}$ mixed with other fatty acid salts [12].

\section{Results and discussion}

\subsection{Antifungal activity of saturated fatty acid salts}

Antifungal effects of saturated fatty acid potassium salts against $T$. violaceum NBRC 31064 are shown for Figure 1. The average initial population of fungi at $0 \mathrm{~min}$ in all samples was approximately $3.0 \times 10^{4} \mathrm{spores} / \mathrm{mL}$. Fungus was incubated for $3 \mathrm{~d}$. Final concentration of fatty acid salts were $175 \mathrm{mM}$. In the saturated fatty acid C6K, $\mathrm{C} 8 \mathrm{~K}, \mathrm{C} 10 \mathrm{~K}, \mathrm{C} 12 \mathrm{~K}$ produced a 4 log-units reduction in the growth of $T$. violaceum NBRC 31064 after incubation for $10 \mathrm{~min}$. Thus, C6K, C8K, C10K, C12K suppressed $99.99 \%$ of fungal growth. C4K produced a 1 log-units reduction in the growth of $T$. violaceum NBRC 31064 after incubation for $180 \mathrm{~min}$. These results show that the compound with the 6 to 12-C chain produced combination the highest antifungal effect. Saturated fatty acid salts exerted an antifungal effect, and no effect was produced by the $\mathrm{pH}$-adjusted solution alone.

No growth samples were cultured up to $10 \mathrm{~d}$. Than this, the high antifungal effect samples was confirmed that there is a persistent. 


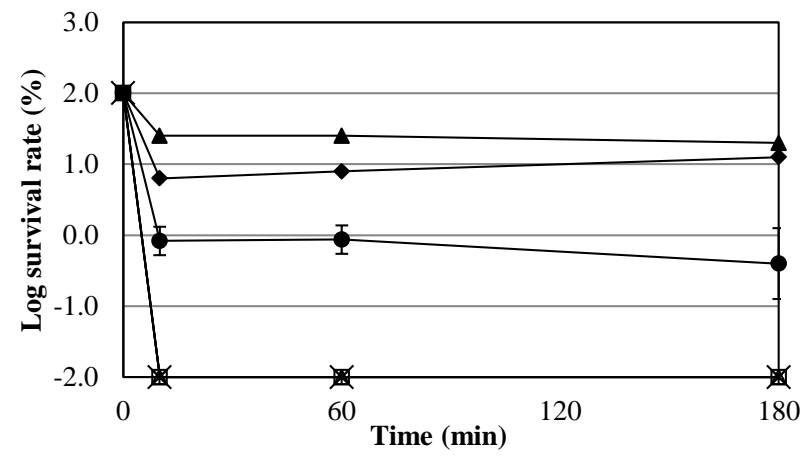

Figure 1. Antifungal activity of $175 \mathrm{mM}$ saturated fatty acid salts against $T$. violaceum NBRC 31064 . Spores were counted at the time of inoculation $(0 \mathrm{~min})$ and after $10,60,180 \mathrm{~min}$ of incubation by means of plating $100 \mu \mathrm{L}$ portions of the same samples. Log survival rate (expressed $\log \mathrm{CFU} / \mathrm{mL}$ ) of the samples stored at $27^{\circ} \mathrm{C}$ for $3 \mathrm{~d}$ were enumerated at the specified time points on Sabouraud dextrose agar. Symbols: $\bullet, \mathrm{C} 4 \mathrm{~K}$; $\square$, $\mathrm{C} 6 \mathrm{~K} ; \Delta, \mathrm{C} 8 \mathrm{~K} ; \times, \mathrm{C} 10 \mathrm{~K} ; *, \mathrm{C} 12 \mathrm{~K} ; \bullet, \mathrm{C} 14 \mathrm{~K} ; \boldsymbol{\Delta}$, Control (KOH pH-adjusted). Experiments were performed in triplicate, and the error bars represent the standard deviation.

In previously reported, Against $P$. pinophilum NBRC 6345, C8K and $\mathrm{C} 12 \mathrm{~K}$ produced an antifungal effect of 2 log-units (suppressing 99\% of growth) following incubation for $180 \mathrm{~min}$. Further, C6K was ineffective after $180 \mathrm{~min}$ [12]. Desbois et al. has been reported for bacteria, it remains unclear exactly how free fatty acids exert their antibacterial activities but the prime target seems to be the bacterial cell membrane [15]. Further the various essential processes that occur within and at the membrane and this allows them to interact with the cell membrane to create transient or permanent pores of variable size [15]. Believes that the effect is also similar in $T$. violaceum.

\subsection{Antifungal activity of unsaturated fatty acid salts}

Antifungal effects of unsaturated fatty acid potassium salts against $T$. violaceum NBRC 31064 are shown for Figure 2. The average initial population of fungi at $0 \mathrm{~min}$ in all samples was approximately $3.0 \times 10^{4} \mathrm{spores} / \mathrm{mL}$. Fungus was incubated for $3 \mathrm{~d}$. Final concentration of fatty acid salts were $175 \mathrm{mM}$. In the unsaturated fatty acid $\mathrm{C} 18: 2 \mathrm{~K}, \mathrm{C} 18: 3 \mathrm{~K}$ produced a 4 log-units reduction in the growth of $T$. violaceum NBRC 31064 after incubation for 10 min. Thus, C18:2K, C18:3K suppressed $99.99 \%$ of fungal growth. $\mathrm{C} 18: 1 \mathrm{~K}$ produced a $1 \mathrm{log}$-units reduction in the growth of $T$. violaceum NBRC 31064 after incubation for $180 \mathrm{~min}$. These results show that the compound with the 18-C cahin has more than 2 double bonds produced combination the highest antifungal effect. Unsaturated fatty acid salts exerted an antifungal effect, and no effect was produced by the $\mathrm{pH}$-adjusted solution alone.

No growth samples were cultured up to $10 \mathrm{~d}$. Than this, the high antifungal effect samples was confirmed that there is a persistent.

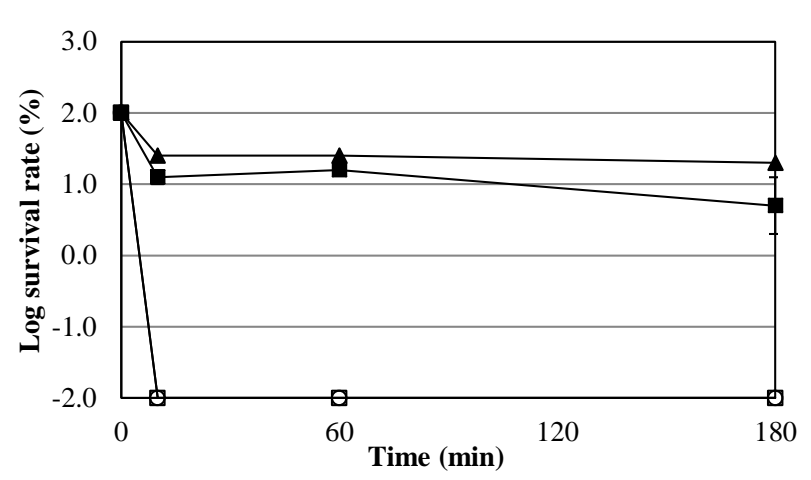

Figure 2. Antifungal activity of $175 \mathrm{mM}$ unsaturated fatty acid salts against $T$. violaceum NBRC 31064 . Spores were counted at the time of inoculation $(0 \mathrm{~min})$ and after $10,60,180 \mathrm{~min}$ of incubation by means of plating $100 \mu \mathrm{L}$ portions of the same samples. Log survival rate (expressed $\log \mathrm{CFU} / \mathrm{mL}$ ) of the samples stored at $27^{\circ} \mathrm{C}$ for $3 \mathrm{~d}$ were enumerated at the specified time points on Sabouraud dextrose agar. Symbols:m, C18:1K; ᄋ, $\mathrm{C} 18: 2 \mathrm{~K} ; \diamond, \mathrm{C} 18: 3 \mathrm{~K} ; \boldsymbol{\Lambda}$, Control (KOH pH-adjusted). Experiments were performed in triplicate, and the error bars represent the standard deviation.

In previously reported, Against $P$. pinophilum NBRC 6345 and $P$. digitatum NBRC 9651, C18:2K and C18:3K were ineffective after $180 \mathrm{~min}$ [12].

\subsection{Antifungal effect of short contact time in the case of saturated fatty acid salts}

Figure 3. showed the antifungal effect against $T$. violaceum NBRC 31064 of fatty acid salts to shorten the incubation. The results of $\mathrm{C} 4 \mathrm{~K}$ was similar to the results of Figure 1. However, C14K produced an antifungal effect of 1log-units (suppressing $90 \%$ of growth) following incubation for $60 \mathrm{sec}$. These results suggest that compound with the 6 to $12-\mathrm{C}$ chain produced and the highest antifungal effect. These results raise the possibility that fatty acid salts was affecting the surface of the cell.

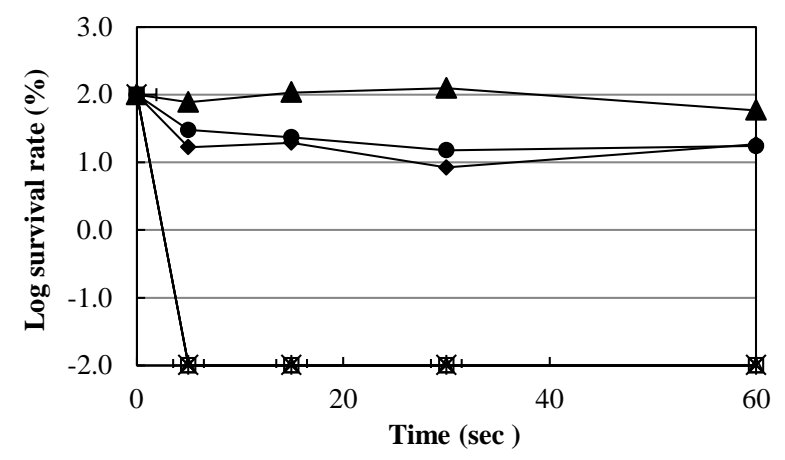

Figure 3. Antifungal activity of $175 \mathrm{mM}$ saturated fatty acid salts against $T$. violaceum NBRC 31064 . Spores were counted at the time of inoculation ( $0 \mathrm{~min})$ and after $5,15,30,60 \mathrm{sec}$ of incubation by means of plating $100 \mu \mathrm{L}$ portions of the same samples. Log survival rate (expressed $\log \mathrm{CFU} / \mathrm{mL}$ ) of the samples stored at $27^{\circ} \mathrm{C}$ for $3 \mathrm{~d}$ were enumerated at the specified time points on Sabouraud dextrose agar. Symbols: $\bullet, \mathrm{C} 4 \mathrm{~K}$; $\square$, $\mathrm{C} 6 \mathrm{~K} ; \Delta, \mathrm{C} 8 \mathrm{~K} ; \times, \mathrm{C} 10 \mathrm{~K} ; *, \mathrm{C} 12 \mathrm{~K} ; \bullet, \mathrm{C} 14 \mathrm{~K} ; \boldsymbol{\Delta}$, Control $(\mathrm{KOH}$ $\mathrm{pH}$-adjusted).

3.4 Antifungal effect of short contact time in the case of unsaturated fatty acid salts 
Figure 4. showed the antifungal effect against $T$. violaceum NBRC 31064 of unsaturated safatty acid salts to shorten the incubation. The results of $\mathrm{C} 18: 1 \mathrm{~K}$ were similar to the results of Figure 1.

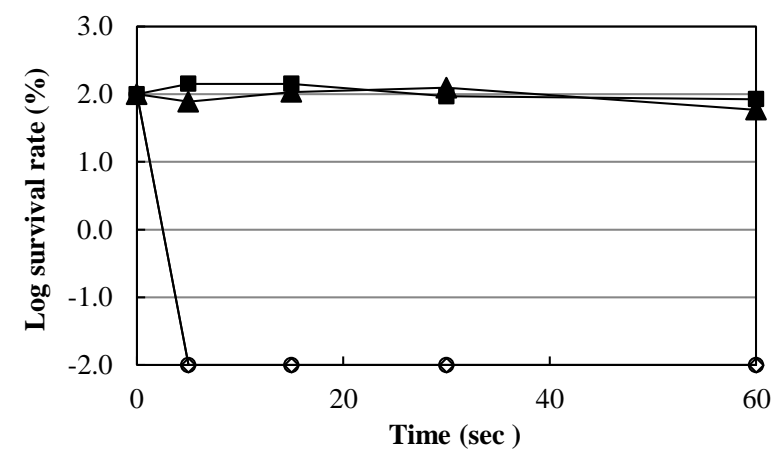

Figure 4. Antifungal activity of $175 \mathrm{mM}$ unsaturated fatty acid salts against $T$. violaceum NBRC 31064 . Spores were counted at the time of inoculation ( $0 \mathrm{~min})$ and after 5, 15, 30, $60 \mathrm{sec}$ of incubation by means of plating $100 \mu \mathrm{L}$ portions of the same samples. Log survival rate (expressed $\log \mathrm{CFU} / \mathrm{mL}$ ) of the samples stored at $27^{\circ} \mathrm{C}$ for $3 \mathrm{~d}$ were enumerated at the specified time points on Sabouraud dextrose agar. Symbols:- $\mathbf{n}$ C18:1K; ○, $\mathrm{C} 18: 2 \mathrm{~K} ; \diamond, \mathrm{C} 18: 3 \mathrm{~K} ; \boldsymbol{\Lambda}$, Control (KOH pH-adjusted).

\subsection{MICs of fatty acid salts and other reagents tested}

Two-fold dilution samples of the $175 \mathrm{mM}$ solution inoculated with fungi were incubated for $10 \mathrm{~min}$, and then applied to the agar medium, and MIC were determined after $7 \mathrm{~d}$ of culture. The experimental results showed that, form the nine fatty acid potassium salts tested, $\mathrm{C} 12 \mathrm{~K}$ and $\mathrm{C} 18: 3 \mathrm{~K}$ had the best antifungal effect against $T$. violaceum NBRC 31064 (Table 1). The MIC of $\mathrm{C} 12 \mathrm{~K}$ and $\mathrm{C} 18: 3 \mathrm{~K}$ were $5.5 \mathrm{mM}$ (Table 1 ). The peak of antifungal effect of saturated fatty acid salts was 12 carbon chain and one more thing the peak of antifungal effect of unsaturated fatty acid salts was 3 double bonds in 18 carbon chain. Similarly, Isaacs et al. reported that fatty acids and monoglycerides containing 8-12 carbons showed stronger antiviral and antibacterial activities than their long-chain counterparts [16]. Desbois et al. investigated the $\mathrm{C} 12$ has the best balance between hydrophobic and hydrophilic groups among saturated fatty acids [17]. Moreover, Zheng et al. suggest that the anti bacterial effect of long-chain unsaturated fatty acids was due to their inhibition of fatty acid biosynthesis [10].

Table 1. MICs of fatty acid salts and other reagents tested against $T$. violaceum NBRC 31064.

\begin{tabular}{|l|c|}
\hline \multicolumn{2}{|c|}{ T. violaceum NBRC 31064 MIC (mM) } \\
\hline \hline Potassium butyrate (C4K) & $>175$ \\
\hline Potassium caprote $(\mathrm{C} 6 \mathrm{~K})$ & 175 \\
\hline Potassium caprylate $(\mathrm{C} 8 \mathrm{~K})$ & 43.8 \\
\hline Potassium caprate $(\mathrm{C} 10 \mathrm{~K})$ & 21.8 \\
\hline Potassium laurate $(\mathrm{C} 12 \mathrm{~K})$ & 5.5 \\
\hline Potassium myristate $(\mathrm{C} 14 \mathrm{~K})$ & $>175$ \\
\hline Potassium oleate $(\mathrm{C} 18: 1 \mathrm{~K})$ & $>175$ \\
\hline Potassium linoleate $(\mathrm{C} 18: 2 \mathrm{~K})$ & 21.8 \\
\hline
\end{tabular}

\begin{tabular}{|l|l|}
\hline Potassium linonate $(\mathrm{C} 18: 3 \mathrm{~K})$ & 5.5 \\
\hline
\end{tabular}

The MIC is the lowest concentration of a drug inhibiting visible growth of spores after 10 min of incubation. MIC, minimum inhibitory concentration.

Suggest that cis double bond increased the activity of a straight-chain fatty acid and, the addition of a second double bond further increased the toxicity of the compounds to grampositive bacteria [18]. Unsaturated fatty acid was potassium linonate $(\mathrm{C} 18: 3 \mathrm{~K})$ was effective. Kodicek reported consistent with us, the toxicity in increasing order: oleic acid < linoleic acid < linolenic acid [19]. However, this does not agree with Kabara et al. Bayliss and Fuller et al. reported that the MIC of linoleic acid was somewhat lower than that of linolenic acid[18], [20], [21]. Thus, these results were suggested that similar to previous results. In the results $P$. pinophilum NBRC 6345 MIC was $175 \mathrm{mM}$ [12]. MIC was better of $T$. violaceum NBRC 31064 that comparison of T. violaceum NBRC 31064 with $P$. pinophilum NBRC 6345. The difference of the effect of the fungi strain has not been clarified. Antifungal effect was not know the different reasons by the fungi strain.

\subsection{Effect of $\mathrm{C} 12 \mathrm{~K}$ mixed with other fatty acid salts}

Soap can be produced using coconut, palm, or olive oils, various fatty acids. Carbon number of fatty acids are generally used the range of 8 to 22 [10]. The main component of soap is fatty acid salts bearing the carbon number and the salts formed from them. The fatty acid salts are characterized by micelle formation at high concentration. The micelle formation depends on the concentration of them, the critical micelle concentration (CMC) of long-chain fatty acid salt is low. Thus, we investigated the effect on the antifungal activity of $\mathrm{C} 12 \mathrm{~K}$ further by studying the antifungal effect of $\mathrm{C} 12 \mathrm{~K}$, which showed the highest antifungal activity, against $T$. violaceum NBRC 31064 when mixed with other salts. Figure. $5(\mathrm{~A}) \sim(\mathrm{H})$ shows the effect of the antifungal activity with mixing $\mathrm{C} 12 \mathrm{~K}$ and other fatty acid salts (C4K, C6K, C8K, C10K, C14K, C18:1K, C18:2K, or $\mathrm{C} 18: 3 \mathrm{~K})$.

$\mathrm{C} 12 \mathrm{~K}$ mixed with $\mathrm{C} 4 \mathrm{~K}$ showed the same antifungal activity (4 log-units) as $\mathrm{C} 12 \mathrm{~K}$ alone (Figure. 5A). Thus, addition of $\mathrm{C} 4 \mathrm{~K}$ did not affect the activity of $\mathrm{C} 12 \mathrm{~K}$. In addition, the effect of mixing $\mathrm{C} 12 \mathrm{~K}$ with $\mathrm{C} 4 \mathrm{~K}$ did not change, regardless of concentration. Similar results were obtained when $\mathrm{C} 12 \mathrm{~K}$ was mixed with short-chain fatty (C6K) and medium-chain fatty acid salts (C8K or C10K) and log-chain fatty acid saits (C14K, C18:2K or $\mathrm{C} 18: 3 \mathrm{~K})$. However addition of long-chain fatty acid salts (C18:1K) inhibited the antifungal activity of $\mathrm{C} 12 \mathrm{~K}$ (Figure. 5F). The antifungal activity of $\mathrm{C} 12 \mathrm{~K}$ decreased when mixed with long-chain fatty acid salts, and decreased more strongly as the concentration of longchain fatty acids increased. However, addition of $3.5 \mathrm{mM}$ of long-chain fatty acid salts did not affect the antifungal activity of $\mathrm{C} 12 \mathrm{~K}$. This may have been due to the low 
concentration; addition of $3.5 \mathrm{mM}$ of any compound did
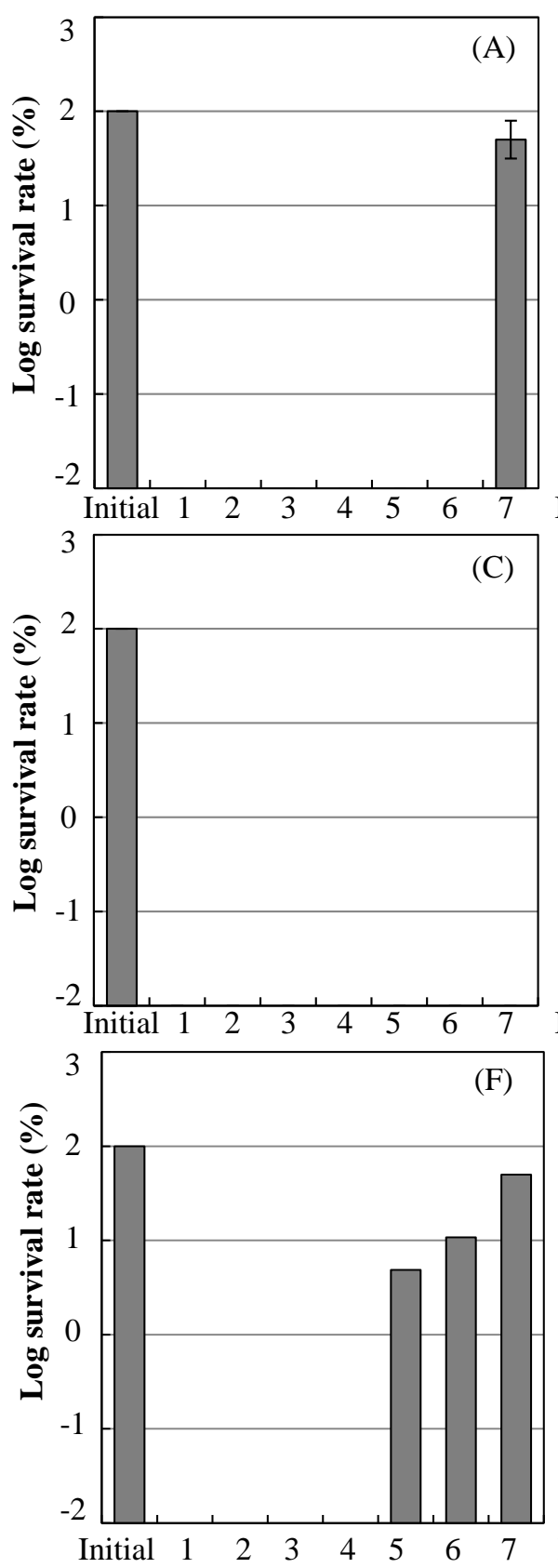

not inhibit C12K.
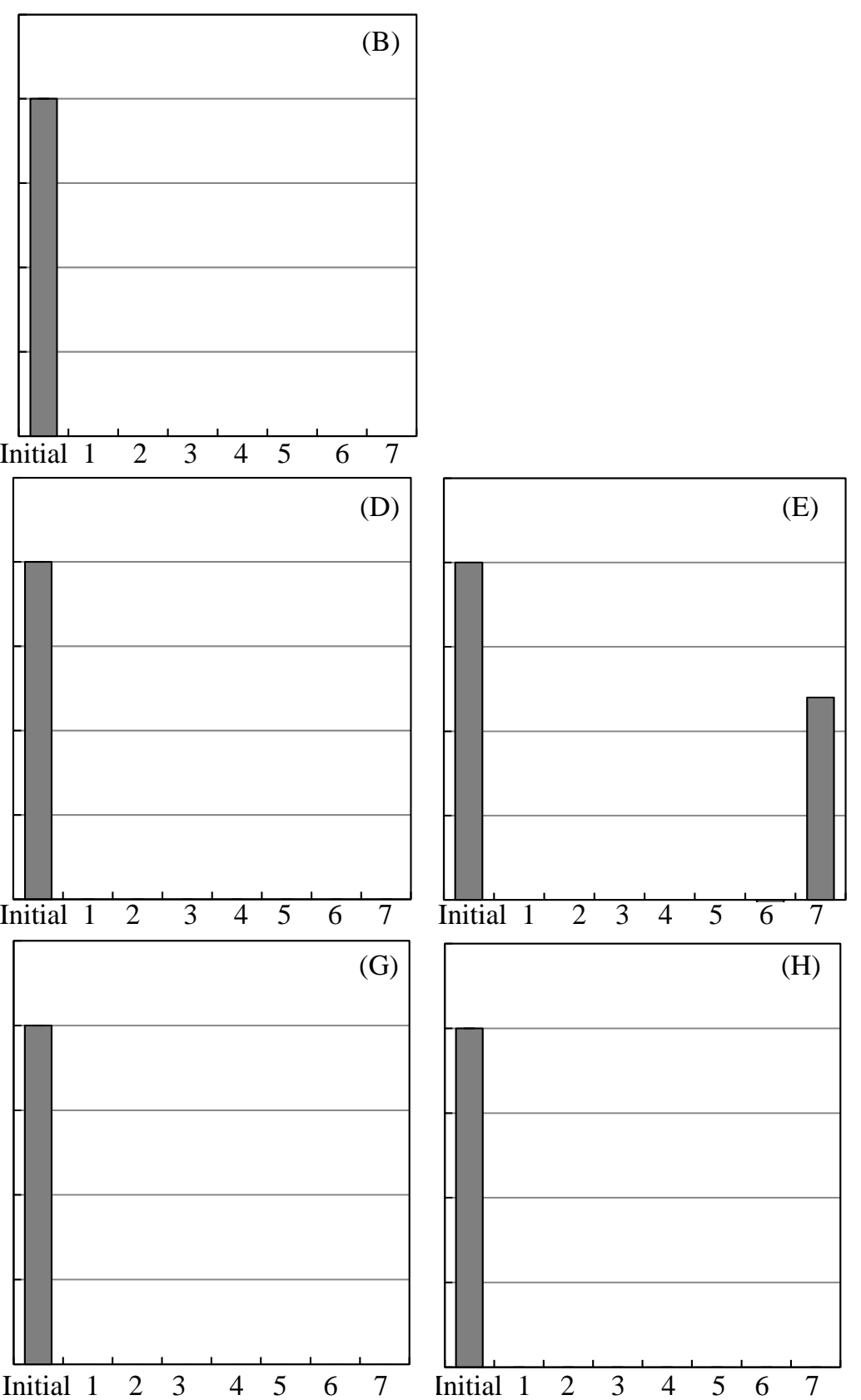

Figures 5. The effect of mixing with other fatty acid salts (C4K, C6K, C8K, C10K, C14K, C18:1K, C18:2K or C18:3K) on the antifungal activity of $\mathrm{C} 12 \mathrm{~K}$. A C12K with $\mathrm{C} 4 \mathrm{~K}, \mathrm{~B}$ C12K with $\mathrm{C} 6 \mathrm{~K}, \mathrm{C} \mathrm{C} 12 \mathrm{~K}$ with C8K, D C12K with C10K, E C12K with $14 \mathrm{~K}, \mathrm{~F}$ C12K with $18: 1 \mathrm{~K}, \mathrm{G} \mathrm{C12K}$ with 18:2K, H C12K with 18:3K. Samples: initial, fungal suspension; sample 1, $5.5 \mathrm{mM} \mathrm{C12K}$ and 0.175 $\mathrm{mM}$ other fatty acid salts; sample $2,5.5 \mathrm{mM} \mathrm{C} 12 \mathrm{~K}$ and $1.75 \mathrm{mM}$ other fatty acid salts; sample $3,5.5 \mathrm{mM} \mathrm{C} 12 \mathrm{~K}$ and $17.5 \mathrm{mM}$ other fatty acid salts; sample $4,5.5 \mathrm{mM} \mathrm{C} 12 \mathrm{~K}$ and $35.0 \mathrm{mM}$ other fatty acid salts; sample $5,5.5 \mathrm{mM} \mathrm{C} 12 \mathrm{~K}$ and $87.5 \mathrm{mM}$ other fatty acid salts; sample 6, $5.5 \mathrm{mM} \mathrm{C12K}$ and $130 \mathrm{mM}$ other fatty acid salts ; sample 7, $175 \mathrm{mM}$ other fatty acid salts alone. Spores were counted at the time of inoculation $(0 \mathrm{~min})$ and after $10 \mathrm{~min}$ of incubation by means of plating $100 \mu \mathrm{L}$ portions of the same samples. Log survival rate (expressed $\log \mathrm{CFU} / \mathrm{mL}$ ) of the samples stored at $27^{\circ} \mathrm{C}$ for $3 \mathrm{~d}$ were enumerated at the specified time points on Sabouraud dextrose agar.

\section{Conclusions}

Of the nine fatty acid salts, saturated fatty acid salts tested, potassium lauric $(\mathrm{C} 12 \mathrm{~K})$ had the most antifungal effect on T. violaceum NBRC 31064, and MIC was 5.5 $\mathrm{mM}$. This is in agreement with the results of several other investigators [18], [20], [22]. C6K, C8K, C10K, C12K and $\mathrm{C} 18: 2 \mathrm{~K}, \mathrm{C} 18: 3 \mathrm{~K}$ can inhibit the ability of $T$. violaceum to take up nutrients, such as amino acids, thereby effectively starving the $T$. violaceum of the nutrients it requires to remain viable [23], [24]. A control solution at the same $\mathrm{pH}$ as the fatty acid salt solutions did not affect fungal growth, and we concluded that the antifungal activity was due to the fatty acid salts themselves, not $\mathrm{pH}$. 
The type of fatty acid salts that act is different it has been confirmed by the species of fungi [12]. Also, it has antifungal effect was revealed that the carbon is from 10 to 12 saturated fatty acid salts.

$\mathrm{C} 4 \mathrm{~K}$ mixed with $\mathrm{C} 12 \mathrm{~K}$, was shown to increase the antifungal effect of C4K (Figure 5A). However, C18 :1K showed a reduction in antifungal effect in the mixture of $35 \mathrm{mM}$ (Figure 5F). The kind of oil used for soap making are beef fas, palm oil, coconut oil, olive oil. It is known that the soap contained many of medium-chain fatty acids and long chain fatty acids [10]. From this study, the soap comprising oleic acid has been shown that low antifungal effect. The experimental results showed the effectiveness of lauric acid salts was prevention for dermatophytes infections. We believe that the fatty acid salt serve the prevention of dermatophytes infection. However, further experiments are required to determine their precise antifungal mechanism.

\section{References}

1. R. Chermette, L. J .G .Ferreiro ; Dermatophytoses in animals. Mycopathologia. 166., 385-405(2008)

2. D. Greenwood, R.C. B. Slack, M. R. Barer, W. L Irving ; Medical microbiology. Aguide to microbial infections palliogenesis, immunity, laboratory diagnosis and control. Ed. 15th ELST publishers. ,558-564 (1997)

3. S.S. Magill, L. Manfredi, A. Swiderski, B. Cohen, W.G. Merz ; Isolation of Trichophyton violaceum and Trichophyton soudanense in Baltimore, Maryland. Journal Clin Microbiol., 45, 461-465 (2007)

4. K. Giddey, M. Monod, J. Barblan, A. Potts, P. Waridel, C. Zaugg, M. Quadroni, Comprehensive Analysis of Proteins Secreted by Trichophyton rubrum and Trichophyton violaceum under in Vitro Conditions. Journal of Proteome Research., 6 , 3081-3092 (2007)

5. B. Fernández-Torres, A. J. Carrillo, E. Martín, A. Del Palacio, M. K. Moore, A. Valverde, M. Serrano, J. Guarro1 ; In Vitro Activities of 10 Antifungal Drugs against 508 Dermatophyte Strains. ANTIMICROBIAL AGENTS AND CHEMOTHERAPY., 45, 2524-2528 (2001)

6. A. Panáčeka, M. Kolářb, R. Večeřováb, R. Pruceka, J. Soukupováa, V. Kryštofc, P. Hamalb, R. Zbořila, L. Kvíteka ; Antifungal activity of silver nanoparticles against Candida spp. Biomaterials., 30, 6333-6340 (2009)

7. S. L. Sado-Kamdem, L. Vannini, M. E. Guerzoni ; Effect of $\alpha$-linolenic, capric and lauric acid on the fatty acid biosynthesis in Staphylococcus aureus. $J$. Food Microbiol., 129, 288-294 (2009)

8. C. H. Pohl, J. L. F. Kock, V. S. Thibane ; Science against microbial pathogens: Commmunicating current Research and technological advances. Formatex Reseach Center., 1, 61-71 (2011)

9. S. Khulusi, H. A. Ahmed, P. Patel, M. A. Mendall, T. C. Northfield, The effects of unsaturated fatty acids on Helicobacter pylori in vitro. J. Med.
Microbiol., 42, 276-282 (1995)

10. C. J. Zheng, J. S. Yoo, T. G. Lee, H. Y. Cho, Y. H. Kim, W. G. Kim ; Fatty acid synthesis is a target for antibacterial activity of unsaturated fatty acids. FEBS Lett., 579, 5157-5162 (2005)

11. C. Altieri, D. Cardillo, A. Bevilacqua, M. Sinigaglia, Inhibition of Aspergillus spp. and Penicillium spp. by fatty acids and their monoglycerides. Journal of Food Protection., 70, 1206-1212 (2007)

12. M. Era, S. Sakai, A. Tanaka, T. Kawahara, T. Kanyama and H. Morita ; Antifungal Activity of Fatty Acid Salts Against Penicillium pinophilum. Japan Journal of Food Engineering., 16, 99-108 (2015)

13. A. Kollanoor, P. Vasudevan, M. K. M. Nair, T. Hoagland, K. Venkitanarayanan ; Inactivation of bacterial fish pathogens by medium chain lipid molecules (caprylic acid, monocaprylin and sodium caprylate). Aquaculture Res., 38, 1293-1300 (2007)

14. K. Takashima ; Mold inspection manual color atlas (Kabi Kensa Manuaru Kara Zufu). Techno System Co., Ltd., 214-215 (2009)

15. A. P. Desbois and V. J. Smith, Antibacterial free fatty acids: Activities, mechanisms of action and biotechnological potential. Applied Microbiology and Biotechnology. 85, 1629-1649 (2009)

16. C. E. Isaacs, R. E. Litov, H. Thormar, Antimicrobial activity of lipids added to human milk, infant formula, and bovine milk. J. Nut. Biochem., 6, 362366 (1995)

17. A. P. Desbois, V. J. Smith ; Antibacterial free fatty acids: activities, mechanisms of action and biotechnological potential. Appl Microbiol Biotechnol., 85, 1629-1642 (2010)

18. J. J. Kabara, D. M. Swieczkwowski, A. J. Conley, and J. Truant, Fatty acids and derivatives as antimicrobial agents. Antimicrob Agents Chemother., 2, 23-28 (1972)

19. E. Kodicek, The effect of unsaturated fatty acids on gram-positive bacteria. Soc. Exp. Biol. Symp., 3, 217-232 (1949)

20. M. Bayliss, Effect of the chemical constitution of soaps upon their germicidal properties. J. Bacteriol. 31, 489-504(1936)

21. R. Fuller, J. H. Moore, The inhibition of the growth of Clostridium welchii by lipids isolated from the contentsof the small intestine of the pig. J. Gen. Microbiol. 46, 23-41 (1967)

22. O. Wyss, B. J. Ludwig, and R. R. Joiner, The fungistaticand fungicidal action of fatty acids and related compounds. Arch. Biochem., 7, 415-425 (1945)

23. H. Galbraith, T. B. Miller, Effect of long chain fatty acids on bacterial respiration and amino acid uptake. Journal of Applied Bacteriology., 36, 659-675 (1973b)

24. I. Shibasaki, N. Kato, Combined effects on antibacterial activity of fatty acids and their esters against Gram-negative bacteria. In: Kabara JJ (ed) Symposium on the pharmacological effect of lipids. The American Oil Chemists' Society, Champaign,19, 15-24 (1978) 